\title{
Retraction Note to: $L C K$ : a new biomarker candidate for the early diagnosis of acute myocardial infarction
}

Fei $\mathrm{Xu}^{1,2} \cdot$ Xiao Teng ${ }^{1} \cdot \mathrm{Xin}_{\text {Yuan }}{ }^{1,2} \cdot$ Jiakang Sun ${ }^{1,2} \cdot$ Hengchao $\mathrm{Wu}^{1,2}$. Zhe Zheng ${ }^{1,2} \cdot$ Yue Tang ${ }^{1,2,3} \cdot$ Shengshou $\mathrm{Hu}^{1,2}$

Published online: 18 August 2015

(C) Springer Science+Business Media Dordrecht 2015

Retraction Note to: Mol Biol Rep (2014) 41:8047-8053

DOI 10.1007/s11033-014-3702-8

The Publisher and Editor retract this article in accordance with the recommendations of the Committee on Publica tion Ethics (COPE). After a thorough investigation we have strong reason to believe that the peer review process was compromised.

The online version of the original article can be found under doi:10.1007/s11033-014-3702-8.

Xin Yuan

weidongzangwz@163.com

$\triangle$ Yue Tang

1 State Key Laboratory of Cardiovascular Disease, Fuwai Hospital, National Center for Cardiovascular Diseases, Beijing 100037, China

2 Department of Surgery, Center for Regenerative Medicine, Fuwai Hospital, Peking Union Medical College, Chinese Academy of Medical Sciences, 167A Beilishi Road, Xicheng District, 100037 Beijing, China

3 Zoopery Center, Fuwai Hospital, Peking Union Medical College, Chinese Academy of Medical Sciences, Beijing 100037, China 